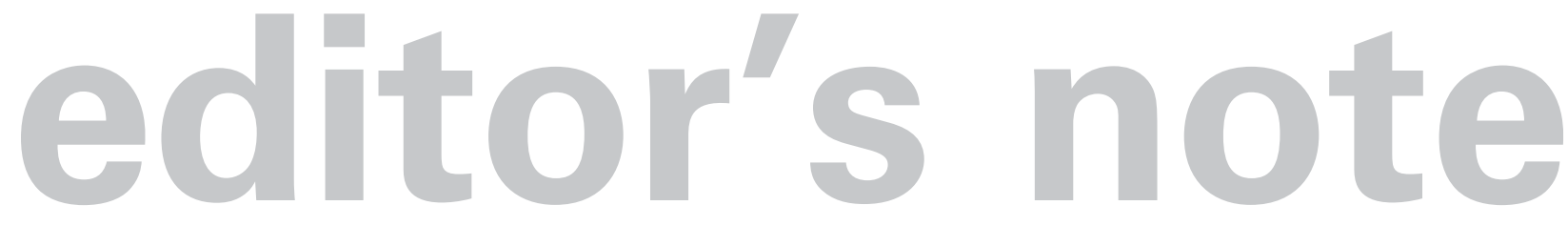

When discussing the handover of the editorship with then editor Gillian Varley, she remarked that we had never had a special issue on Australasia, and I accepted her comment as a challenge. We have had over the years single contributions from Australia and New Zealand but never enough at one time to create a whole issue. There has been sporadic contact with colleagues there but it has never come together ... until now. True it is still not a whole issue devoted to Australasian art library culture, but with a couple of contributions from the IFLA Art Libraries Section satellite session in Kuala Lumpur in 2018, we have definitely moved to the other side of the world.

A conference in a city like Kuala Lumpur offers a superb opportunity to see collections in Asia and gives the Art Libraries Journal the opportunity to feature authors from the region. Vandana Sinha treats us to a trip along an ancient thoroughfare documenting the architectural richness of Mughal travellers' resting stops along a route that now straddles both India and Pakistan. We are then brought into the 20th century by Sulaiman Esa, a visual artist who responded to the call of an energetic, new country by offering up his work, rooted in religious conviction, in the service of nation-building.

Moving further along early trade routes brings us to Australia, where Arlis/ANZ held its biennial conference in October 2018. It was great luck to make contact with the speakers on the programme, many of whom have contributed to this issue, introducing us to their collections and some of the issues they are facing in their practice.

Romany Manuell and her colleagues are grappling with the lack of diversity in their design library collection at Monash University, which is a reflection of an outdated curriculum. The topic is familiar to many of us but is, perhaps, felt more acutely given the diversity of its population and the historic treatment of its indigenous cultures. The project is still in its early stages, but will inform future collection policies.

Several articles focus on engaging audiences by showcasing their unique visual and archival material. On this precise theme Caroline McBride of the Auckland Art Gallery Toi o Tāmaki discusses identifying opportunities to share the gallery's archival collections and attract new audiences. A similar approach is taken by Peta Jane Blessing and Simon Underschultz of the National Gallery of Art in Australia in meeting the demands of internal and external researchers for original and archival material that has long been hidden within the special collections and archives.

The resurgence of interest in botanical illustration plays right into Jane Black's hands as she flaunts beautiful examples of both historic and contemporary illustrations held in the Australian National Botanic Gardens Library and Archives.

The theme running through all these articles is sharing the depth of information about the collections held in their institutions' libraries and archives and this is continued as Lucy Hawthorne presents a practical solution to storing and sharing her museum's internal collection and exhibition information, while Tim Jones describes the Christchurch Art Gallery's overhaul of their audioguide programme.

It has been a long time coming and this taster of art libraries in Australasia, not to mention the rich collections of museums and libraries in Asia, has merely whetted our appetites.

\title{
Erica Foden-Lenahan
}

